\title{
Acute Kidney Injury during Malaria in Togolese Children
}

\section{Kossi Akomola Sabi1, Befa Noto Kadou Kaza1 ${ }^{*}$, Eyram Yoan Makafui Amekoudi ${ }^{1}$, Weu Melanie Tia², Jacques Vigan³, Hamat Ibrahim4, Guillaume Abderhamman Mahamat", Sandra Amouzou-Glikpa', Edem Djadou ${ }^{5}$}

\author{
${ }^{1}$ Service de néphrologie et hémodialyse, CHU SylvanusOlympio, Lomé, Togo \\ ${ }^{2}$ Service de néphrologie et d'hémodialyse, CHU de YOPOUGON, Abidjan, République de Côte d'Ivoire \\ ${ }^{3}$ Clinique de néphrologie, CNHU, Cotonou. Bénin \\ ${ }^{4}$ Service de néphrologie et d'hémodialyse, hôpital universitaire de N'djaména, Tchad \\ ${ }^{5}$ Service de pédiatrie, CHU SylvanusOlympio, Lomé, Togo \\ Email: kossi.sabi@gmail.com, ^bfanotokadoukaza@yahoo.fr, eyramyoan@gmail.com, amelitia@gmail.com, \\ jacquesvigan@gmail.com
}

How to cite this paper: Sabi, K.A., Kaza, B.N.K., Amekoudi, E.Y.M., Tia, W.M., Vigan, J., Ibrahim, H., Mahamat, G.A., Amouzou-Glikpa, S. and Djadou, E. (2018) Acute Kidney Injury during Malaria in Togolese Children. Open Journal of Nephrology, 8, 85-93.

https://doi.org/10.4236/ojneph.2018.84010

Received: August 5, 2018

Accepted: November 10, 2018

Published: November 13, 2018

Copyright $\odot 2018$ by authors and Scientific Research Publishing Inc. This work is licensed under the Creative Commons Attribution International License (CC BY 4.0).

http://creativecommons.org/licenses/by/4.0/

\begin{abstract}
Objective: To describe clinical, biological and evolutionary profile of Acute Kidney Injury (AKI) due to Severe Malaria in the pediatric department. Methodology: This was a retrospective descriptive study that took place from January to December 2012. It has been included children aged 0 - 15 years admitted for severe malaria with positive thick drop. AKI was defined by using the modified RIFLE (Risk Injury Failure Loss End stage) classification for Pediatrics. Results: 338 children admitted for severe malaria were included. AKI was diagnosed in 24 children, a prevalence of $7.1 \%$ according to pRIFLE classification: RISK in 10 (3\%), INJURY in $9(2.6 \%)$ and FAILURE in 5 (1.5\%). The average age was $8.16 \pm 4.2$ years. Clinical features were dominated by hemoglobinuria in $87.5 \%$, oliguria, vomiting and fever in $75 \%$. The biological features were dominated by severe anemia $(\mathrm{Hb}<6 \mathrm{~g} / \mathrm{dl})$ in $79.2 \%$ of cases. Hyperkalemia $(\mathrm{K}>5.5 \mathrm{mmol} / \mathrm{l})$ was found in 2 cases. The mean parasitic density was 22,120 trophozoites. Malaria was treated primarily with artemether in $83.3 \%$ of the cases. Dialysis was indicated in 2 cases for menacing hyperkalaemia, but was not done because of lack of financial means. In one case, hyperkalaemia was successfully treated with symptomatic measures, but in the second case, these measures were not allowed to normalize kalaemia, and death occurred. Conclusion: Acute post-malarial renal failure secondary to tubular necrosis may be the dominant clinical features of severe malaria. Death may occur. Preventing malaria would be the best way to avoid it.
\end{abstract}




\section{Keywords}

AKI, Severe Malaria, Haemoglobinuria, Togo

\section{Introduction}

Malaria, the first parasitic endemic in the world, still remains a major public health problem, with sub-Saharan Africa accounting for $80 \%$ of the 300 millions of malaria cases reported in the world in 2012 [1]. According to World Health Organization (WHO) global estimations in 2012, 1,000,000 deaths occurred and majority of them among children were less than five years old [1]. Acute kidney injury (AKI) is a common complication of severe malaria (SM) in adults, affecting up to $40 \%$ of patients [1] [2]. In the absence of appropriate renal replacement therapy (RRT), the case fatality rate approaches 75\% [1] [2]. Clinically and pathologically, AKI in adults with SM resembles acute tubular necrosis [3]. In the world, there are limited data on the incidence of AKI in pediatric SM with estimates ranging from 3\% to $31 \%$ [4] [5] [6] [7]. In Africa, the few existing data estimates AKI in pediatric SM between $23 \%$ and 45\% [2] [7]. In Togo, there are only two old epidemiological studies which concerned severe pediatric malaria in general [8]. Our study, the first of its kind in Togo, aims to describe clinical, biological and evolutionary profile of AKI due to SM in the pediatric department of Sylvanus Olympio Teaching Hospital of Lome.

\section{Methodology}

This was a retrospective descriptive study that took place from January to December 2012 in the pediatric department of Sylvanus Olympio Teaching Hospital of Lome. Have been included children aged 0 - 15 years admitted for severe malaria with positive thick drop. Included were all records of both sexes, aged 0 - 15 years, admitted for severe malaria with associated or not to signs of kidney damage such as oliguria, anuria, haematuria, hemoglobinuria, facial edema, or edema of the lower limbs. Not included in our study children admitted for severe malaria with a thick negative drop, those admitted in pediatric with positive thick drop without renal failure. Data concerned sociodemographic, clinical, biological, therapeutic and evolutionary were collected. AKI was defined by using the modified RIFLE (Risk Injury Failure Loss End stage) classification for Pediatrics (pRIFLE): estimated creatinine clearance (calculated according to Schwartz formula) decreased by at least $25 \%$, or diuresis $<0.5 \mathrm{ml} / \mathrm{kg} / \mathrm{h}$ for 8 hours [9]. When the Creatinine is unknown, the decline in the estimated GFR (Glomerular Filtration $\mathrm{R}$ ate) was calculated from of a reference value of $100 \mathrm{ml} / \mathrm{min} / 1.73 \mathrm{~m}^{2}$ (Table 1).

\section{Statistical software}

The Statistical software SPSS 18.0 was used for the analysis of the data. Student $t$ test (two tailed, independent) has been used to find the significance of 
Table 1. pRIFLE classification of AKI.

\begin{tabular}{ccc}
\hline & Estimated CrCl & Urine output \\
\hline Risk & eCrCl decrease by $25 \%$ & $<0.5 \mathrm{ml} / \mathrm{kg} / \mathrm{h}$ for $8 \mathrm{~h}$ \\
Injury & $\mathrm{eCrC}$ decrease by $50 \%$ & $<0.5 \mathrm{ml} / \mathrm{kg} / \mathrm{h}$ for $16 \mathrm{~h}$ \\
Failure & $\mathrm{eCrC}$ decrease by $75 \%$ or & $<0.3 \mathrm{ml} / \mathrm{kg} / \mathrm{h}$ for $24 \mathrm{~h}$ or anuric for $12 \mathrm{~h}$ \\
& $\mathrm{eCrCl}<35 \mathrm{ml} / \mathrm{min} / 1.73 \mathrm{~m}^{2}$ & \\
Loss & Persistent failure $>4$ weeks & \\
End stage & End-stage renal disease & \\
& (persistent failure $>3$ months) & \\
\hline
\end{tabular}

$\mathrm{eCrCl}$, estimated creatinine clearance; pRIFLE, pediatric risk, injury, failure, loss and end-stage renal disease.

study parameters on continuous scale between two groups (Inter group analysis) on metric parameters. Chi square/Fisher Exact test has been used to find the significance of study parameters on categorical scale between two or more groups.

\section{Results}

During the study period 338 children admitted for severe malaria were included. AKI was diagnosed in 24 children, a prevalence of $7.1 \%$ according to pRIFLE classification: RISK in 10 (3\%), INJURY in $9(2.6 \%)$ and FAILURE in 5 (1.5\%) (Table 2).

The sex ratio was 2.43 with an average age of $8.16 \pm 4.2$ years (Figure 1 ).

The rate of self-medication recovered is high (Table 3 ).

At admission, clinical features were dominated by hemoglobinuria in $87.5 \%$, oliguria, vomiting and fever in $75 \%$. Hypotension was found in $37.5 \%$ of the cases (Table 4).

The biological features were dominated by severe anemia $(\mathrm{Hb}<6 \mathrm{~g} / \mathrm{dl})$ in $79.2 \%$ of cases. Hyperkalemia $(\mathrm{K}>5.5 \mathrm{mmol} / \mathrm{l})$ was found in 2 cases with a context of anuria in one case (Table 4). All the thick drops were positive to Plasmodium Falciparum. The mean parasitic density was 22,120 trophozoites with extremes of 190 and 98,810 parasites $/ \mathrm{mm}^{3}$. For treatment, $25 \%$ of patients received quinine treatment before admission. During hospitalization, $58.3 \%$ of children needed blood transfusion. Malaria was treated primarily with artemether in $83.3 \%$ of the cases (Table 5).

Dialysis was indicated in 2 cases for menacing hyperkalaemia, but was not done because of lack of financial means. In one case, hyperkalaemia was succefully treated with symptomatic measures (insulin in glucose serum, furosemide, bicarbonate serum). In the second case, these measures not allowed to normalize kalaemia because of anuria, and finally death occurred. In all other cases, renal function was recovered in $91.6 \%$. Only one child had kidney function below 30 $\mathrm{ml} / \mathrm{min} / 1.73 \mathrm{~m}^{2}$ after 3 weeks. $\mathrm{H}$ was referred to nephrologist for follow-up (Figure 2).

Malaria was treated effectively in all cases attested by a negative thick dropscontrol after an average stay of $16 \pm 4.4$ days. 
Table 2. Prevalence of AKI stratified by the pRIFLE definition.

\begin{tabular}{ccc}
\hline pRIFLE & Prevalence & Average of eCrCl \\
\hline No AKI & $314(92.9 \%)$ & $104 \mathrm{ml} / \mathrm{min} / 1.73 \mathrm{~m}^{2}$ \\
Risk & $10(3 \%)$ & $58 \mathrm{ml} / \mathrm{min} / 1.73 \mathrm{~m}^{2}$ \\
Injury & $3(2.6 \%)$ & $38.7 \mathrm{ml} / \mathrm{min} / 1.73 \mathrm{~m}^{2}$ \\
Failure & $5(1.5 \%)$ & $17.4 \mathrm{ml} / \mathrm{min} / 1.73 \mathrm{~m}^{2}$
\end{tabular}

eCrCl, estimated creatinine clearance; pRIFLE, pediatric risk, injury, failure, loss and end-stage renal disease.

Table 3. Antecedents distribution.

\begin{tabular}{cc}
\hline Antecedent & $\mathrm{N}=24$ \\
\hline HTA & $0(0 \%)$ \\
Diabetes & $0(0 \%)$ \\
Allergie to quinine & $1(4.2 \%)$ \\
Self-medication & $14(58.3 \%)$ \\
No & $9(37.5 \%)$ \\
\hline
\end{tabular}

Table 4. Distribution according pattern, clinical and biological data of admission.

\begin{tabular}{|c|c|}
\hline Pattern/Data & $\mathrm{N}=24$ \\
\hline \multicolumn{2}{|l|}{ Extra renal origin } \\
\hline Fever $>38^{\circ} \mathrm{C}$ & $18(75 \%)$ \\
\hline Hypotension & $9(37.5 \%)$ \\
\hline Prostration & $9(37.5 \%)$ \\
\hline Vomiting & $18(75 \%)$ \\
\hline Convulsion & $10(41.6 \%)$ \\
\hline Icteria & $10(41.6 \%)$ \\
\hline \multicolumn{2}{|l|}{ Renal origin } \\
\hline Oliguria $(<12 \mathrm{ml} / \mathrm{kg} / 24 \mathrm{~h})$ & $18(75 \%)$ \\
\hline Edema & $3(12.5 \%)$ \\
\hline Hemoglobinuria & $21(87.5 \%)$ \\
\hline \multicolumn{2}{|l|}{ Biology data } \\
\hline Anemia $(<6 \mathrm{~g} / \mathrm{dl})$ & $19(79.2 \%)$ \\
\hline Thrombopenia $\left(<150,000 / \mathrm{mm}^{3}\right)$ & $18(75 \%)$ \\
\hline Hyperleukocytosis $\left(>10,000 / \mathrm{mm}^{3}\right)$ & $10(41.6 \%)$ \\
\hline Hyperbilirubinemia (>2 mg/l) & $9(37.5 \%)$ \\
\hline $\operatorname{ASAT}(\geq 1.5 \mathrm{~N})$ & $21(87.5 \%)$ \\
\hline $\operatorname{ALAT}(\geq 1.5 \mathrm{~N})$ & $9(37.5 \%)$ \\
\hline Hyponatremia $(<135 \mathrm{mmol} / \mathrm{l})$ & $3(12.5 \%)$ \\
\hline Hyperkaliemia (>5.5 mmol/l) & $2(8.3 \%)$ \\
\hline Urea $(\geq 1 \mathrm{mmol} / \mathrm{l})$ & $2(8.3 \%)$ \\
\hline
\end{tabular}

ASAT: aspartate aminotransferase; ALAT: Alanine aminotransferase. 
Table 5. Treatment received before and during hospitalization.

\begin{tabular}{cc}
\hline Type of treatement & $\mathrm{N}=24$ \\
\hline Before hospitalization & $6(25 \%)$ \\
Quinine & $2(8.33 \%)$ \\
Artemether & $5(20.83 \%)$ \\
Analgesics & $2(8.33 \%)$ \\
Anticonvulsivants & $1(4.17 \%)$ \\
Traditionnal & \\
During hospitalization & \\
Symptomatic & $14(58.33 \%)$ \\
Transfusion & $4(16.67 \%)$ \\
Diuretic & \\
Antimalarial & $20(83.33 \%)$ \\
Artemether & $4(16.66 \%)$ \\
Quinine &
\end{tabular}

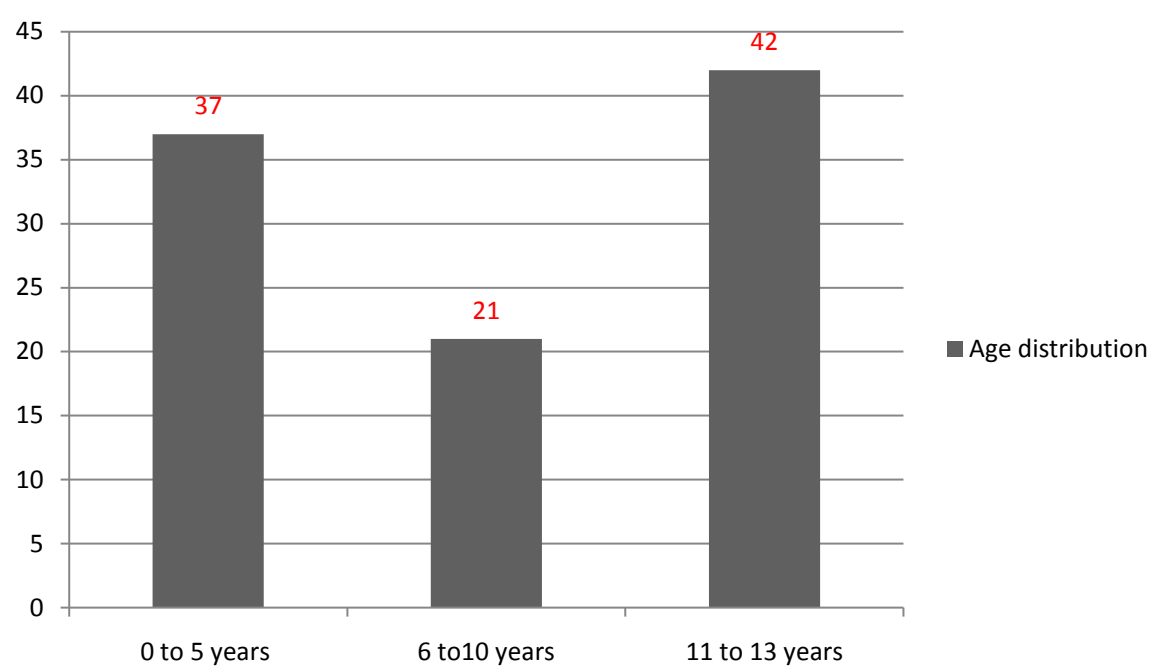

Figure 1. Age distribution.

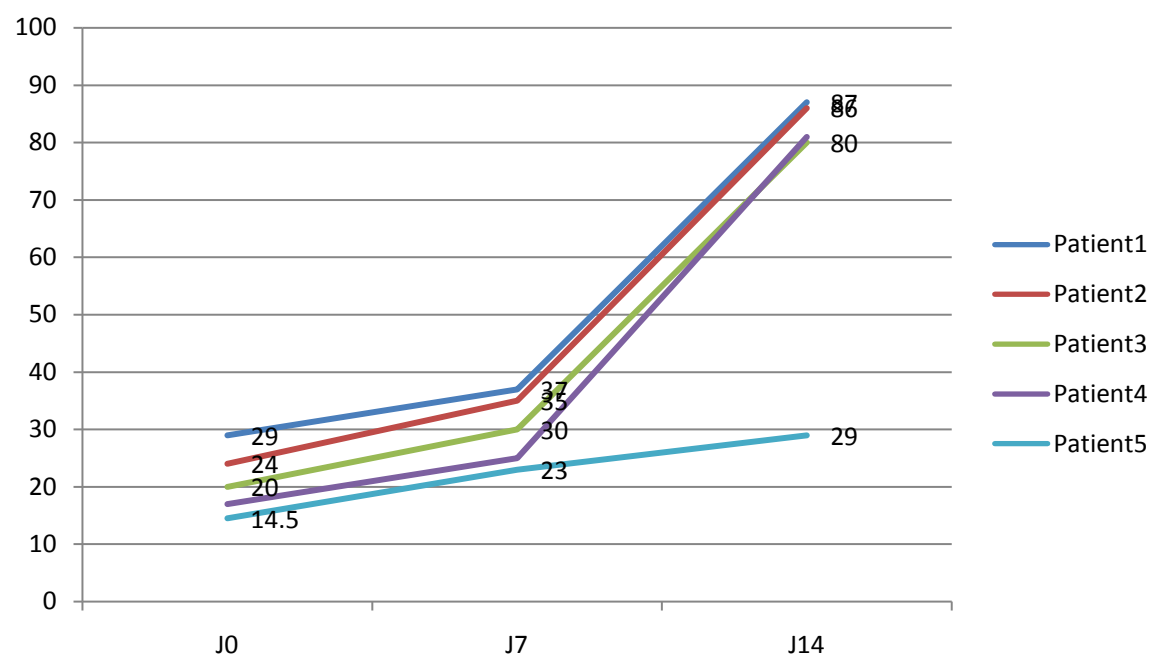

Figure 2. Evolution of renal function of children classified Failure. 


\section{Discussion}

In endemic areas of Malaria, AKI is a common complication, but there are limited data on the incidence of AKI in pediatric SM with estimates ranging from $3 \%$ to $31 \%$ [4] [5] [6] [7] [10]. In Togo, our study is the first which talk about this item. The prevalence of AKI due to severe malaria is $7.1 \%$ in our study, lower than the $23.6 \%$ found in the Congo [7] or the $30.4 \%$ found in India [11]. This difference would probably be related to the retrospective nature of our study. Our prevalence is nevertheless more important than that of several works of the 2000s [8] [12] [13], suggesting that the association of AKI with malaria would be a new factor. This hypothesis is supported in several studies which prove the resurgence in endemic area of bilious fever hemoglobinuria which was considered in the years 1950-1970 erroneously as only the disease of nonimmune subjects to malaria [7] [14] [15] [16]. The average age of our patients was 8 years, similar to that reported in the study by Bodi et al. [15]. AKI is predominant in our study by the early stages of the RIFLE classification ( $R$ and I stages: 19 of 24 patients, 79.2\%), which shows a large part of functional renal failure in pathophysiology of AKI during malaria. Moreover, hypotension was present in $37 \%$ of cases, vomiting in $75 \%$ and severe anemia in $79 \%$. In the literature, hemoglobinuria, which prevalence remains high in studies [7] [13] [15], including our study (87\%), is the main pathogenesis of acute renal failure during malaria. This hemoglobinuria resulting from intravascular haemolysis is not the only mechanism of AKI due to malaria. It resulting from many factors such as: cytoadherence and erythrocyte sequestration with intravascular coagulation, responsible for hypo-perfusion; dehydration and hypovolemia related to fever, profuse sweating, lack of water supply and digestive disorder, also leading to renal hypo-perfusion; Activation of monocytes with release of cytokines, free radicals and immunoglobulins. These phenomena contribute to the establishment of acute tubular necrosis in malaria [7]. In our study, nearly one quartz of patients had been treated with quinine (25\%) and analgesic (20\%), which could be another factor of AKI. The hemolyzing effect of quinine is known in particular hemoglobinopathies [7] [14] [15] [17] [18]. The majority of our patients have been treated with artemether with total effectiveness. However, 2 patients presented hyperkalaemia requiring emergency dialysis, but not realized due to lack of financial means leading to the death of one patient. The problem of lack of care in emergency dialysis is recurring in Togo where until now there is only one hemodialysis center for the whole country [19]. Patients pay for their hemodialysis sessions themselves. There is only one adult nephrologist per 7 million inhabitants [19]. Peritoneal dialysis, normally adapted to children, is not available. The mortality in our study is $4.16 \%$, different from the results of Ivoiry Coast, Nigeria and Congo where it is above 10\% [7] [14] [20]. The average hospital stay is $16+4.4$ days, similar to the results of Kunuanunua [7]. Classic duration of acute tubular necrosis evolution is the explanation. Of the 24 patients collected, $95 \%$ fully recovered renal function. A single patient who has not fully recovered 
will gradually progress to chronic renal failure and will be an additional burden on the already dying health system. The weakness of study is it's retrospective nature. Obviously the size of our sample does not allow us to make relevant statistical tests.

\section{Conclusion}

Acute renal failure often secondary to tubular necrosis may be the dominant clinical feature of severe malaria. Death may occur; its prognosis depends on early diagnosis and the prompt introduction of adequate treatment. As always, malaria prevention would be the best way to avoid it. In Togo the setting up of a structure adapted to the management of acute kidney failure in general and especially adapted to pediatrics will improve the prognosis of this pathology of which our study shows only the part emerged from the iceberg because of its retrospective and monocentric character.

\section{Availability of Data and Materials Section}

All data generated or analyzed during this study are included in this published article.

\section{Acknowledgements}

No particular acknowledgment.

\section{Ethics and Consent Statement}

Not applicable.

\section{Funding}

No funding was received.

\section{Author's Contribution}

All authors have contributed to a published study to conception and design, acquisition of data, analysis and interpretation of data, drafting the manuscript, revising it critically for important intellectual content and have given final approval of the version to be published.

\section{What Is Already Known about This Topic?}

In the world, there are limited data on the incidence of Acute Kidney Injury (AKI) in pediatric Severe Malaria (SM). In Africa, the existing data is very limited.

\section{What This Study Adds?}

Our study, the first of its kind in Togo, aims to describe clinical, biological and evolutionary profile of AKI due to SM in the pediatric department of Sylvanus 
Olympio Teaching Hospital of Lome. Our paper discusses the possibility to develop peritoneal dialysis in this country.

\section{Conflicts of Interest}

The authors of this manuscript have no conflicts of interest to disclose as described by the OJNEPH.

\section{References}

[1] Yakpa, W.F. (2012) Malaria and Pregnancy in Togo. http://ao.um5s.ac.ma/xmlui/handle/123456789/1827

[2] Conroy, A.L., Hawkes, M., Robyn, E., Elphinstone, Morgan, C., Hermann, L., Barker, K.R., Namasopo, S., et al. (2016) Acute Kidney Injury Is Common in Pediatric Severe Malaria and Is Associated with Increased Mortality. Open Forum Infectious Diseases, 3, ofw046. https://doi.org/10.1093/ofid/ofw046

[3] Nguansangiam, S., Day, N.P., Hien, T.T., et al. (2007) A Quantitative Ultrastructural Study of Renal Pathology in Fatal Plasmodium falciparum Malaria. Tropical Medicine \& International Health, 12, 1037-1050. https://doi.org/10.1111/j.1365-3156.2007.01881.x

[4] Kapoor, K. and Gupta, S. (2012) Malarial Acute Kidney Injury in a Paediatric Intensive Care Unit. Tropical Doctor, 42, 203-205. https://doi.org/10.1258/td.2012.120196

[5] Imani, P.D., Odiit, A., Hingorani, S.R., et al. (2013) Acute Kidney Injury and Its Association with In-Hospital Mortality among Children with Acute Infections. Pediatric Nephrology, 28, 2199-2206. https://doi.org/10.1007/s00467-013-2544-2

[6] Zaki, S.A., Shenoy, P., Shanbag, P., et al. (2013) Acute Renal Failure Associated with Malaria in Children. Saudi Journal of Kidney Diseases and Transplantation, 24, 303-308. https://doi.org/10.4103/1319-2442.109585

[7] Kunuanunua, T.S., Nsibu, C.N., Gini-Ehungu, J.L., et al. (2013) Acute Renal Failure and Severe Malaria in Congolese Children Living in Kinshasa, Democratic Republic of Congo. Néphrologie \& Thérapeutique, 9, 160-165. https://doi.org/10.1016/j.nephro.2013.01.001

[8] Assimadi, J.K., Gbadoé, A.D., Atakouma, D.Y., Agbénowossi, K., Lawson-Evi, K., Gayibor, A. and Kassankogno (1998) [Severe Malaria in Children in Togo]. Archives de Pediatrie, 5, 1310-1315. https://doi.org/10.1016/S0929-693X(99)80048-7

[9] Akcan-Arikan, A., Zappitelli, M., Loftis, L.L.,Washburn, K.K., Jefferson, L.S. and Goldstein, S.L. (2007) Modified RIFLE Criteria in Critically Ill Children with Acute Kidney Injury. Kidney International, 71, 1028-1035. https://doi.org/10.1038/sj.ki.5002231

[10] Olowu, W.A. and Adelusola, K.A. (2004) Pediatric Acute Renal Failure in Southwestern Nigeria. Kidney International, 66, 1541-1548. https://doi.org/10.1111/j.1523-1755.2004.00918.x

[11] Kochar, D.K., Gajanand, S.T., Poonam, C.K., Sanjay, K.K., Ghanshyam, S.S., Anjana, G. and Abhishek, K. (2010) Clinical Features of Children Hospitalized with Malaria: A Study from Bikaner, Northwest India. The American Journal of Tropical Medicine and Hygiene, 83, 981-989. https://doi.org/10.4269/ajtmh.2010.09-0633

[12] Erunkulu, O.A., Hill, A.V., Kwiatkowski, D.P., Todd, J.E., Iqbal, J., Berzins, K., Riley, M. and Greenwood, B.M. (1992) Severe Malaria in Gambian Children Is Not Due 
to Lack of Previous Exposure to Malaria. Clinical and Experimental Immunology, 89, 296-300. https://doi.org/10.1111/j.1365-2249.1992.tb06948.x

[13] Gbadoé, A.D., Kini-Caussi, M., Koffi, S., Traoré, H., Atakouma, D.Y., Tatagan-Agbi, K. and Assimadi, K.J. (2006) [Evolution of Severe Pediatric Malaria in Togo between 2000 and 2002]. Medicine et Maladies Infectieuses, 36, 52-54. https://doi.org/10.1016/j.medmal.2005.10.006

[14] Daubrey-Potey, T.H., Die-Kacou, H., Kamagate, M., Vamy, M., Balayssac, E. and Yavo, J.C. (1990) [Blackwater Fever during Antimalarial Treatment in Abidjan (West Africa): Report of 41 Cases]. Bulletin de laSociete de PathologieExotique, 97, 325-328.

[15] Bodi, J.M.., Nsibu, C.N., Aloni, M.N., Lukute, G.N., Kunuanuna, T.S,. Tshibassu, P.M. and Pakasa, N. (2014) Black Water Fever Associated with Acute Renal Failure among Congolese Children in Kinshasa. Saudi Journal of Kidney Diseases and Transplantation, 25, 1352-1358. https://doi.org/10.4103/1319-2442.144326

[16] Aloni, M.N., Celestin, N.N., Meeko-Mimaniye, M., Ekulu, P.M., et al. (2012) Acute Renal Failure in Congolese Children: A Tertiary Institution Experience. Acta Paediatrica, 101, e514-e518. https://doi.org/10.1111/j.1651-2227.2012.02827.x

[17] Djadou, K.E., Komlangan, A., Balaka, B., Dokounor, D., Gbadoe, A.D., Atakouma, D., Agbere, A.D., Kessie, K. and Assimadi, K. (2006) Management of Severe Malaria in Children at Tsévié Regional Hospital Center (Togo). Archives de pédiatrie, 13, 1555-1556. https://doi.org/10.1016/j.arcped.2006.09.010

[18] Al-Mendalawi, M.D. (2013) Acute Renal Failure Associated with Malaria in Children. Saudi Journal of Kidney Diseases and Transplantation, 24, 1255. https://doi.org/10.4103/1319-2442.121298

[19] Sabi, K.A., Noto-Kadou-Kaza, B., Amekoudi, Y.E., Tsevi, M.C., Kossidze, K. and Amedegnato, D. (2014) [Epidemiologic and Clinical Profile of Patients at Their First Consultation with a Nephrologist in Togo]. Médecine et Santé Tropicales, 24, 169-171.

[20] Naqvi, R., Ejaz, A., Fazal, A., Anwar, N. and Adib, R. (2003) Outcome in Severe Acute Renal Failure Associated with Malaria. Nephrology Dialysis Transplantation, 18, 1820-1823. https://doi.org/10.1093/ndt/gfg260

\section{Abreviations}

AKI: Acute Kidney Injury; SM: Severe Malaria; RIFLE: Risk Injury Failure Loss End stage. 